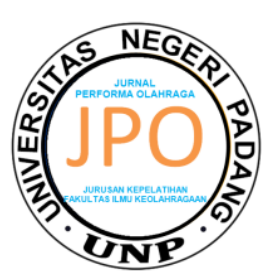

Jurnal PerformaOlahraga

ISSN Online : 2714-660X ISSN Cetak : 2528-6102

Journal Homepage :http://performa.ppj.unp.ac.id/index.php/kepel

Volume 5 Nomor 2, 2020, Hlm 130-136

DOI: https://doi.org/10.24036/jpo155019

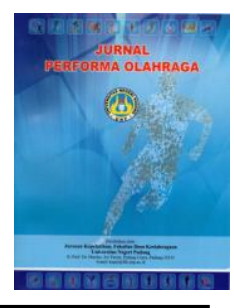

\title{
PENGARUH LATIHAN PLYOMETRICS TERHADAP PENINGKATAN KEMAMPUAN FREETHROW
}

\author{
Ade Frashetya Mahendra ${ }^{1}$, Alex Aldha Yudi ${ }^{2}$, Witarsyah ${ }^{3}$, Sari Mariati ${ }^{4}$ \\ ${ }^{1}$ Fakultas Ilmu Keolahragaan, Universitas Negeri Padang, Indonesia
}

\section{Informasi Artikel}

Diterima 2020-11-23

Direvisi 2021-02-06

Dipublikasikan 2021-03-19

\section{Keyword:}

Plyometrics Training

Freethrow Ability

\begin{abstract}
Problem in this study is the lack of ability Free throwathletes sons SMA $\mathrm{N} 12$ Padang. The variables in this study are training plyometrics andability free throw. The purpose of this study was to determine the effect oftraining plyometrics on the improvement of theability of free throw male athletes at SMA N 12 Padang. This type of research is a quasi-experimental that aims to see the effect oftraining plyometrics on improvingability Freethrow's. The population in this study were all basketball athletes at SMA N 12 Padang totaling 30 people.Sampling was done by purposive sampling technique, namely male athletes of SMA N 12 Padang as many as 10 people.To obtain research data, theability test was used Free throw. The data obtained were analyzed by using the $t$ test. Based on the results of data analysis, it is known thatexercise plyometrics thishas a significant effect on increasing the ability of free throws. Where theaverage of pre-test theability free throw was 1.9, while the post test increased to 4.1. Then obtained the mean difference test ( $t$ test) of $t_{\text {count }} 7.09$ while $t_{\text {table }} 2.26$ with a significant level $\alpha=0.05$ and $n=10$, then $t_{\text {count }}>t_{\text {table }}(7.09>2.26)$, it can be concluded that there is a significant effect of the form oftraining plyometrics on the improvement ofability free throw in male basketball athletes at SMA N 12 Padang.
\end{abstract}

(C) 2020 The Authors. Published by Universitas Negeri Padang.

This is an open access article under the CC BY-NC-SA license (https://creativecommons.org/licenses/by-nc-sa/4.0/

\section{Penulis Korespondensi:}

Ade Frashetya Mahendra

Universitas Negeri Padang

Email: adefrashetya3246@gmail.com

\section{PENDAHULUAN}

Pendidikan merupakan kegiatan yang universal dalam kehidupan manusia, karena dimanapun di dunia terdapat pendidikan. Kemajuan ilmu dan teknologi menimbulkan perubahan yang cepat dalam berbagai tatanan kehidupan manusia, sehingga terjadinya globalisasi dan pasar bebas (Ridwan, M., \& Irawan, R 2018). Pendidikan olahraga saat ini telah mengalami kemajuan yang sangat pesat. Olahraga telah memasuki semua aspek kehidupan seperti industri, perkenomian, dan pendidikan. Indonesia merupakan salah satu negara yang sedang giat-giatnya melaksanakan pembangunan di segala bidang. Salah satu bidang diantaranya adalah pembangunan di bidang olahraga.

Olahraga memerlukan suatu proses yang relatif lama di antaranya melalui training atau latihan. Latihan (training) juga diartikan oleh Palar, C. M., Wongkar, D., \& Ticoalu, S. H.(2015) bahwa latihan didefinisikan sebagai aktivitas olahraga secara sistematis yang dilakukan berulangulang dalam jangka waktu lama disertai dengan peningkatan beban secara bertahap dan terusmenerus sesuai dengan kemampuan masing-masing individu, tujuannya adalah untuk membentuk 
dan mengembangkan fungsi fisiologis dan psikologis.Latihan adalah proses kerja yang dilakukan secara sistematis dan berkesinambungan.Beban atau intensitasnya semakin hari semakin bertambah agar memberikan rangsangan secara menyeluruh terhadap tubuh. Latihan fisik yang dilakukan dengan tepat, terukur, dan teratr serta dengan asupan gizi yang cukup akan meningkatkan kebugaran (Putri, A. E., Donie, D., Fardi, A., \& Yenes, R. 2020).Menurut Priyono, R. E., \& Yudi, A. A. (2019) menjelaskan bahwa latihan adalah suatu proses penyempurnaan atlet secara sadar untuk mencapai mutu prestsi maksimal.

Bolabasket merupakan olahraga yang menggunakan bola besar, dimainkan dengan tangan, yang bisa dimainkan oleh lima orang tiap regu putra atau putri.Permainan Bolabasket terdiri dari teknik-teknik dasar yaitu; Passing, Shooting, dan dribbling. Bolabasket merupakan permainan dengan gerakan yang kompleks yaitu gabungan dari jalan, lari dan lompat serta unsur kekuatan, kecepatan, ketepatan, kelentukan, keseimbangan dan lain-lain (Wulandari, M., \& Umar, 2020). Basketball adalah olahraga tim multifaset yang membutuhkan kebugaran anaerobik yang berkembang dengan baik untuk dimainkan dengan sukses (Khlifa, R., Aouadi, R., Hermassi, S., Chelly, M. S., Jlid, M. C., Hbacha, H., \&Castagna, C. 2010). Nuryadi, A(2016) Berpendapat tentang bermain bolabasket seperti jenis olahraga lainnya, untuk dapat bermain bolabasket setiap orang yang ingin menekuni olahraga tersebut, terlebih dahulu harus menguasai beberapa keterampilan dasar dalam permainan bolabasket seperti passing, dribble, dan shoting. Semakin baik seorang atlet dapatmelakukan berbagai teknik yang mendasari permainan seperti dribling, shooting, passing dan sebagainya, maka semakin memiliki peluang untuk sukses. Tetapi keahlian khusus ini akan terbatas bila atlet memiliki kondisi fisik yang lemah. Gerakan yang efektif dan bisa efisien dalam permainan bolabasket merupakan suatu tujuan dalam penguasaan teknik dasar yang baik.Menurut Oktavianus, I., Bakhtiar, S., \& Bafirman, B. (2018) beberapa teknik dasar yang perlu diketahui dalam permainan Bolabasket adalah sebagai berikut: Passing (teknik melempar dan menangkap bola), Dribling (teknik menggiring bola), Shooting (teknik menembak), Pivot (berputar badan dengan salah satu kaki sebagai poros), Foot work (teknik pergerakan kaki); Jumping (melompat), Rebounding (teknik merayah bola), Intercept (teknik memotong arah passing bola), Steals (teknik merebut bola). Secara garis besar bahwa teknik dasar bermain Bolabasket terdiri dari: (a) Passing (mengoper); (b) Dribbling (menggiring); (c) Shooting (menembak); (d) Rebounding (merayah).

Di dalam Ma'sum,R. A., Fardi, A., Sin, T. H., \& Witarsyah, W. (2020) Olahraga prestasi adalah Kegiatan olahraga yang dilakukan dan dikelola secara profesional dengan tujuan untuk memperoleh prestasi yang optimal pada cabang-cabang olahraga tertentu.Menurut Lesmana, H. S., Afrizal, S., \& Mariati, S. (2020) Pembinaan dan perkembangan dibidang olahraga harus dikembangkan sedini mungkin, untuk menciptakan generasi-generasi muda yang berprestasi dan mengharumkan nama bangsa.Salah satunya pada cabang olahragabolabasket. Peningkatan prestasi dalam bolabasket hanya akan berhasil jika didukung oleh kemampuan kondisi yang baik. Situasi ini harus diterapkan dan dilatih berulang kali. Kemenangan suatu tim ditentukan dari seberapa bisa mereka bekerja sama dengan baik (Ramos, M., Yenes, R., Donie, D., \& Oktavianus, I. (2020).

Kondisi Atlet bolabasket yang memiliki kondisi fisik yang bagus akan dapat lebih cepat menguasai teknik-teknik dalam olahraga yang ditekuninya, karena latihan taktik, teknik serta keterampilan akan mampu dilakukan secara maksimal. Artinya meskipun harus mengulangi teknik atau taktik berulang kali,atlet tidak akan merasa cepat lelah. Oleh karena itu, program latihan kondisi fisik harus ditata, dirancang, dan dilakukan dengan baik agar mampu meningkatkan kondisi kebugaran jasmani dan kemampuan biomotorik yang dibutuhkan. Dalam setiap cabang olahraga khususnya bolabasket, ada salah satu komponen fisik yang harus dilatih dengan baik yaitu power.

Menurut Maidarman (2017) daya ledak otot mempunyai peranan penting dalam cabang olahraga yang membutuhkan kontraksi otot yang kuat dan cepat. Daya ledak otot merupakan perpaduan antara kekuatan dan kecepatan. Afrizal, S. (2018)berpendapat bahwa daya ledak otot merupakan komponen kondisi fisik yang sangat perlu diperhatikan oleh pelatih dalam meningkatkan prestasi atlet. Dalam olahraga bolabasket, power sangat berperan penting karena dapat meningkatkan kemampuan otot tungkai maupun otot tangan yang sangat dibutuhkan, salah satunya dalam free throw, free throw merupakan unsur yang memerlukan komponen kondisi fisik 
yang baik supaya saat melakukanya memperoleh hasil yang bagus. Kemampuan free-throw bola basket dipengaruhi oleh power tungkai, power lengan, dan koordinasi mata tangan (Fauzi, R. 2019). Oleh karena itu, banyak bentuk latihan yang digunakan untuk meningkatkan kemampuan otot tungkai dan otot tangan, akan tetapi pola latihan plyometrics adalah salah satu bentuk latihan yang dapat digunakan dalam olahraga bolabasket. Menurut Hanafi, S. (2010) Latihan plyometrics dapat dilakukan untuk mengembangkan power bisa dengan cara mengembangkan kecepatan memelihara kekuatan atau mengembangkan kekuatan dan memelihara kecepatan. Latihan plyometrics bertujuan untuk meningkatkan kecepatan dan kekuatan. Dinata, N. (2019) Latihan plyometrics merupakan suatu bentuk latihan yang umum digunakan untuk meningkatkan kemampuan daya ledak otot (power) otot tungkai.

Berdasarkan pengamatan peneliti pada saat mengikuti kejuaraan dipertandingan terakhir SMA 12 Padang di SMA 2 cup 2019, atlet SMA 12 mempunyai masalah pada tembakan freethrow dimana rendahnya field goals free throw oleh atlet SMA 12 Padang disebabkan karena bola hasil free throw yang tidak menyentuh ring lawan (air ball) oleh atlet, dan akurasi free throw yang tidak tepat dilakukan oleh atlet. Melihat kenyataan ini maka dapat dilihat bahwa rendahnya kemampuan daya ledak otot tungkai dan daya ledak otot tangan menjadi salah satu faktor penghambat bagi atlet untuk menciptakan skor lewat free throw. Menurut Yenes, R., Syahara, S., \& Kiram, Y. (2018)ada tiga manfaat dari permainan bolabasket yaitu fisik, mental dan juga sosial karena banyaknya ivent yang bersifat kompetisi baik lokal maupun internasional. Latihan plyometrics adalah jenis olahraga yang mengharuskan atlet untuk melompat atau bergerak aktif. Menurut (Lockie, R. G., Murphy, A. J., Callaghan, S. J., \& Jeffriess, M. D. 2014) Pelatihan plyometrics dapat memberikan penekanan yang lebih besar pada produksi gaya berdiri, dengan latihan seperti melompat dan melompat menghasilkan gaya reaksi tanah (GRF) yang jauh lebih besar jika dibandingkan dengan lari cepat maksimal. Latihan plyometrics menawarkan banyak manfaat untuk tubuh, terutama untuk kekuatan dan kecepatan. Karakteristik organisasi dari metodologi ini memungkinkan pelatih untuk dengan mudah mengawasi latihan beban dan plyometrics dalam satu latihan pada hari yang sama (Santos, E.J., \& Janeira, M. A. 2008). Dengan latihan plyometrics yang terprogram dan pemilihan bentuk latihan yang tepat, tim/klub dapat meningkatkan daya ledak otot tungkai maupun daya ledak otot lengan atlet-atletnya dengan baik agar memudahkan atlet dalam melakukan teknik freethrow. Meskipun plyometrics dapat menjadi metode pelatihan yang efektif untuk meningkatkan kekuatan otot, kecepatan, kelincahan, dan kekuatan, mekanisme yang tepat di mana plyometrics dapat menurunkan risiko cedera lutut dan meningkatkan plyometrics dalam tim pemain bola basket kurang dipahami. Namun demikian, tidak ada studi yang berfokus pada analisis program plyometrics tertentu yang dilaksanakan pramusim untuk meningkatkan kinerja pada pemain bolabasket (Asadi, A., de Villarreal, E. S., \& Arazi, H. 2015).

Atas dasar hal inilah maka masalah utama yang harus dipecahkan ialah memberi latihan plyometrics dan meneliti terkait dengan pengaruh latihanplyometrics terhadap peningkatan kemampuan freethrow Atlet Bolabasket Putra SMAN 12 Padang.

\section{METODE}

Penelitian ini merupakan penelitian eksperimen semu yang dilakukan terhadap atlet bolabasket putra SMAN 12 Padang. Populasi dalam penelitian ini adalah seluruh atlet SMAN 12 Padang yang bejumlah 30 orang. Sampel pada penelitian ini adalah atlet junior putra SMAN 12 Padang yaitu sebanyak 10 orang, dengan teknik purposive sampling. Instrument tes yang digunakan dalam penelitian ini adalah tes freethrow 5 kali tembakan, sedangkan teknik analisis data statistik yang digunakan dalam penelitian ini adalah uji normalitas liliefors dan uji t dengan taraf signifikan $\alpha=0,05$.

\section{HASIL DAN PEMBAHASAN}

\section{Pre Test dan Post Test Kemampuan Freethrow}

Pengukuran pre test kemampuan free throw dilakukan sebelum diberikan perlakuan, yaitu bentuk latihan plyometrics kepada sampel 10 atlet putra SMA N 12 Padang. Dari hasil pengukuran pre test kemampuan free throw tersebut didapat, yaitu nilai minimal 1 dan nilai maksimal 3. Kemudian diperoleh juga mean sebesar 1,9 dan standar deviasi sebesar 0,737. 
Kemudian pengukuran post test kemampuan free throw dilakukan setelah mendapatkan perlakuan, yaitu bentuk latihan plyometrics selama 12 kali pertemuan kepada sampel 10 atlet putra SMA N 12 Padang. Dari hasil pengukuran post test kemampuan free throw tersebut didapat, yaitu nilai minimal 3 dan nilai maksimal 5. Kemudian diperoleh juga mean sebesar 4,1 dan standar deviasi sebesar 0,737.

Tabel 1. Distribusi Frekuensi Peningkatan Kemampuan Free throw

\begin{tabular}{|c|c|c|c|c|c|}
\hline \multirow{2}{*}{ No } & \multirow{2}{*}{ Kelas Interval } & \multicolumn{2}{|c|}{ Pre Test } & \multicolumn{2}{c|}{ Post Test } \\
\cline { 3 - 6 } & $\begin{array}{c}\text { Absolut } \\
\text { (Fa) }\end{array}$ & Relatif (\%) & $\begin{array}{c}\text { Absolut } \\
\text { (Fa) }\end{array}$ & Relatif (\%) \\
\hline 1 & $0-1$ & 3 & $30 \%$ & 0 & $0,00 \%$ \\
\hline 2 & $2-3$ & 7 & $70 \%$ & 2 & $20 \%$ \\
\hline 3 & $4-5$ & 0 & $0,00 \%$ & 8 & $80 \%$ \\
\hline \multicolumn{2}{|c|}{ Jumlah } & 10 & $100 \%$ & 10 & $100 \%$ \\
\hline
\end{tabular}

Berdasarkan pada tabel 1 distribusi frekuensi pre test dari 10 atlet sampel, atlet memiliki skor kemampuan free throw dengan perolehan nilai berkisar antara 0-1 ada (30\%). 7 atlet (70\%) memiliki skor kemampuan free throw dengan perolehan nilai berkisar antara 2-3. Sedangkan atlet memiliki skor kemampuan three point shoot dengan perolehan nilai berkisar antara 4-5 tidak ada (0,00\%).

Kemudian distribusi frekuensi post test dari 10 atlet sampel, atlet yang memiliki skor kemampuan free throw dengan perolehan nilai berkisar antara $0-1$ tidak ada (0,00\%). 2 atlet (20\%) memiliki skor kemampuan free throw dengan perolehan nilai berkisar antara 2-3.8 atlet (80\%) memiliki skor kemampuan free throwdengan perolehan nilai berkisar antara 4-5.

\section{Uji Normalitas}

Uji normalitas dilakukan dengan menggunakan uji liliefors dengan taraf nyata $(\alpha)=0,05$. Kriteria pengujiannya adalah bahwa tolak hipotesis nol jika Lobservasi (Lo) yang diperoleh dari data pengamatan melebihi Ltabel (Lt) dan sebaliknya terima hipotesis nol apabila Lobservasi (Lo) yang diperoleh lebih kecil dari Ltabel (Lt) secara sederhana dapat digunakan rumus sebagai berikut:

Ha ditolak jika, Lobservasi (Lo)> Ltabel(Lt)

Ha diterima jika, Lobservasi (Lo) $<$ Ltabel (Lt)

Tabel 2. Uji Normalitas Data Kemampuan Free throw

\begin{tabular}{|l|l|l|l|l|l|}
\hline No & Variabel & $\mathrm{N}$ & Lo & Lt & Distribusi \\
\hline 1 & $\begin{array}{l}\text { Kemampuan Free throw } \\
\text { (Pre Test) }\end{array}$ & 10 & 0,244 & 0,258 & Normal \\
\hline 2 & $\begin{array}{l}\text { Kemampuan Free throw } \\
\text { (Post Test) }\end{array}$ & 10 & 0,255 & 0,258 & Normal \\
\hline
\end{tabular}

Tabel 2 menunjukkan bahwa hasil pengujian untuk pengukuran pre test kemampuan free throw skor Lo $=0,244$ dengan $n=10$, sedangkan Ltabel pada taraf pengujian signifikan $\alpha=0,05$ diperoleh 0,258 yang lebih besar dari Lo. Sehingga disimpulkan bahwa skor kemampuan free throw berasal dari populasi yang berdistribusi normal dan dapat digunakan untuk pengujian hipotesis penelitian. 
Untuk pengukuran post test kemampuan free throw skor Lo=0,255 dengan $n=10$, sedangkan Ltabel pada taraf pengujian signifikan $\alpha=0,05$ diperoleh 0,258 yang lebih besar dari Lo. Sehingga disimpulkan bahwa skor kemampuan free throw berasal dari populasi yang berdistribusi normal dan dapat digunakan untuk pengujian hipotesis penelitian.

\section{Pengujian Hipotesis}

Hipotesis yang diajukan adalah terdapat pengaruh latihan dari latihan plyometrics terhadap peningkatan kemampuan free throw pada atlet putra SMA N 12 Padang. Berdasarkan analisis komparasi dengan rumus uji beda mean (uji t) yang dilakukan maka diperoleh hasil analisis uji beda mean (ujit) sebagai berikut:

Tabel 3. Rangkuman Hasil Pengujian Hipotesis

\begin{tabular}{|c|c|c|c|c|c|c|}
\hline \multicolumn{2}{|c|}{ Variabel } & $\begin{array}{c}\text { Rata- } \\
\text { rata }\end{array}$ & $\mathrm{N}$ & $\begin{array}{c}\text { thitun } \\
\mathrm{g}\end{array}$ & ttabel & Keterangan \\
\hline $\begin{array}{c}\text { Kemampuan } \\
\text { Free throw }\end{array}$ & $\begin{array}{c}\text { Pre } \\
\text { Test }\end{array}$ & 1,9 & \multirow{2}{*}{10} & 7,09 & 2,26 & Signifikan \\
\cline { 2 - 7 } & $\begin{array}{c}\text { Post } \\
\text { Test }\end{array}$ & 4,1 & & & \\
\hline
\end{tabular}

Tabel 3 menunjukkan besar pengaruh latihan plyometrics terhadap peningkatan kemampuan free throw atlet putra SMA N 12 Padang dengan rata-rata pre test sebesar 1,9 dan post test nya meningkat menjadi 4,1 (meningkat 2,2). Kemudian hasil analisis uji beda mean (uji t) sebesar thitung 7,09 sedangkan ttabel sebesar 2,26 dengan taraf signifikan $\alpha=0,05$ dan $n=10$. Berdasarkan pengambilan keputusan di atas maka thitung $>\operatorname{ttabel}(7,09>2,26)$. Dapat dikatakan bahwa terdapat pengaruh latihan plyometrics yang berarti terhadap peningkatan kemampuan free throwatlet putra SMAN 12 Padang.

\section{Pembahasan}

Berdasarkan hasil penelitian yang dilakukan di lapangan, membuktikan bahwa terdapat pengaruh latihan plyometrics terhadap peningkatan kemampuan free throw atlet putra SMA N 12 Padang. Sebelum diberikan perlakuan terhadap sampel, terlebih dahulu diketahui kemampuan maksimal atlet pada setiap bentuk latihan, kemudian dilakukan tes awal. Berdasarkan hasil tes tersebut ternyata kemampuan free throw diperoleh rata-rata pada saat pre test yaitu sebesar 1,9. Namun setelah diberikan perlakuan dengan latihan plyometrics maka terjadi peningkatan dengan rata-rata menjadi 4,1 .

Hal ini diperkuat setelah dilakukan uji t, dimana diperoleh hasil thitung sebesar 7,09 yang lebih besar dari ttabel dalam taraf $\alpha=0,05$ sebesar 2,26. Dengan hasil penelitian ini berarti hipotesis yang diajukan dapat diterima kebenarannya, dalam kalimat lain dapat disimpulkan bahwa latihan plyometrics memberikan pengaruh yang signifikan terhadap peningkatan kemampuan free throw atlet putra SMA N 12 Padang.

Plyometrics merupakan latihan yang dilakukan untuk meningkatkan daya ledak otot yang sangat dibutuhkan dalam beberapa cabang olahraga, istilah ini sering digunakan dalam menghubungkan gerakan lompat yang berulang-ulang atau latihan untuk menghasilkan reaksi yang eksplosive. Tujuan latihan plyometrics adalah untuk merangsang berbagai macam perubahan dalam system syaraf otot, meningkatkan stabilitas kelompok-kelompok otot untuk merespon lebih cepat dan bertenaga dalam perubahan-perubahan singkat dan cepat pada panjang otot.

Pada cabang olahraga bolabasket, untuk menghasilkan kemampuan free throw yang baik sangat dibutuhkan unsur daya ledak otot. Apabila seseorang pemain memiliki daya ledak otot yang baik, maka dapat membantu kecepatan gerak tangan untuk mengarahkan dan mengusahakan agar bola masuk ke sasaran serta membantu atlet melakukan tolakan lompatan pada saat melakukan free throw. Oleh karena itu sangat diperlukan latihan plyometrics dalam bolabasket agar mendapatkan 
daya ledak otot yang baik agar dapat melakukan teknik-teknik dalam bolabasket salah satunya yaitu free throw.

Tidak terlepas dari hasil yang diperoleh pada penelitian ini, faktor-faktor yang berkaitan dengan proses latihan juga sangat mempengaruhi hasil yang dicapai, seperti intensitas, durasi, beban latihan, serta frekuensi dalam latihan itu sendiri. Karena masing-masing faktor tersebut turut berperan terhadap kelangsungan latihan yang terprogram.

\section{KESIMPULAN}

Berdasarkan hasil penelitian, maka penulis memberikan beberapa saran agar dapat membantu mengatasi masalah yang ditemui dalam peningkatan kemampuan Freethrow atlet putra SMA N 12 Kota Padang yaitu: Bagi pelatih bolabasket SMA N 12 Kota Padang untuk dapat menggunakan latihan plyometrics dalam meningkatkan kemampuan Freethrow atlet putra SMA N 12 Kota Padang. Bagi atlet putra SMA N 12 Kota Padang perlunya memperhatikan latihan plyometrics untuk dapat meningkatkan kemampuan Freethrow agar termotivasi dan lebih semangat dalam berlatih.

\section{DAFTAR PUSTAKA}

Afrizal, S.(2018).Dayaledak Otot Tungkai Dan Kelentukan Berkontribusi Terhadap Akurasi Shooting Sepakbola.Performa, 3(02),81-81.

Asadi,A., de Villarreal, E.S., \& Arazi, H.(2015).The effects of plyometric type neuromuscular training on postural control performance of male team basketball players. The Journal of Strength \& Conditioning Research, 29(7), 1870-1875.

Dinata, N.(2019).Pengaruh Latihan Plyometrics Terhadap Kemampuan Long Passing Pemain Sepakbola. Jurnal Patriot, 2(4), 840-850.

Fauzi,R.(2019).Hubungan Power Tungkai, Power Lengan, dan Koordinasi Mata Tangan Dengan Kemampuan Free-Throw Bola Basket Pada Mahasiswa PJKR Unsoed (Doctoral dissertation, Universitas Jenderal Soedirman).

Hanafi, S. (2010). Efektifitas latihan beban dan latihan pliometrik dalam meningkatkan kekuatan otot tungkai dan kecepatan reaksi. Jurnal Ilara, 1(2), 1-9.

Khlifa, R., Aouadi, R., Hermassi, S., Chelly, M.S., Jlid, M.C., Hbacha, H., \& Castagna, C.(2010). Effects of a plyometric training program with and without added load on jumping ability in basketball players. The Journal of Strength \& Conditioning Research, 24(11), 2955-2961.

Lesmana, H. S., Afrizal, S., \& Mariati, S.(2020).TINJAUAN KEMAMPUAN TEKNIK DASAR ATLET BOLABASKET. Jurnal Patriot, 2(3), 825-836.

Lockie,R.G., Murphy, A.J., Callaghan, S.J., \& Jeffriess, M.D. (2014).Effects of sprint and plyometrics training on field sport acceleration technique.The Journal of Strength \& Conditioning Research, 28(7), 1790-1801.

Maidarman, M.(2017).KONTRIBUSI DAYA LEDAK OTOT TUNGKAI DAN KELENTUKAN PINGGANG TERHADAP KEMAMPUAN START RENANG GAYA BEBAS ATLET WOMENS SWIMMING CLUB. Performa, 2(01), 13-21.

Ma'sum,R. A., Fardi,A., Sin, T.H., \& Witarsyah, W.(2020).Pengaruh Metode Latihan Sirkuit Terhadap Kemampuan OpenSmash Atlet Bolavoli Klub Guntur 1000 Kota Padang.Jurnal Patriot, 2(3), 885-897.

Nuryadi,A.(2016).PENGARUH LATIHAN PLYOMETRICS TERHADAP PENINGKATAN KETERAMPILAN LAY-UP BOLABASKET. WAHANA, 66(1), 1-5.

Oktavianus, I., Bakhtiar, S., \& Bafirman, B. (2018). Bentuk Latihan Pliometrik, Latihan Beban Konvensional Memberikan Pengaruh terhadap Kemamampuan Three Point Shoot Bolabasket. Performa, 3(01), 21-21. 
Palar, C. M., Wongkar, D., \& Ticoalu, S. H. (2015). Manfaat latihan olahraga aerobik terhadap kebugaran fisik manusia. eBiomedik, 3(1).

Priyono,R.E., \& Yudi, A.A.(2019).Pengaruh Latihan Plyometric Terhadap Jauhnya Tendangan Long Pass.Jurnal Patriot, 2(3), 554-564.

Putri,A.E., Donie, D., Fardi, A., \& Yenes, R.(2020).METODE CIRCUIT TRAINING DALAM PENINGKATAN DAYA LEDAK OTOT TUNGKAI DAN DAYA LEDAK OTOT LENGAN BAGI ATLET BOLABASKET.Jurnal Patriot, 2(3), 680-691.

Ramos,M., Yenes, R., Donie, D., \& Oktavianus, I.(2020).Kontribusi Daya Ledak Otot Tungkai dan Keseimbangan Terhadap Kemampuan Jump Shoot Bolabasket. Jurnal Patriot, 2(3), 837-847.

Ridwan,M., \& Irawan, R.(2018).Validitas Dan Reliabilitas Tes Kondisi Fisik Atlet Sekolah Sepakbola (Ssb)Kota Padang “ Battery Test Of Physical Conditioning” .Performa, 3(02), 90-90.

Santos, E. J., \& Janeira, M. A. (2008). Effects of complex training on explosive strength in adolescent male basketball players. The Journal of Strength \& Conditioning Research, 22(3), 903-909.

Wulandari,M., \& Umar, U.(2020).Pengaruh Latihan Air Alert Terhadap Kemampuan Jump Shoot Pemain Bolabasket Klub Andromeda Padang. Jurnal Patriot, 2(2), 389-398.

Yenes,R., Syahara, S., \& Kiram, Y.(2018).Pengaruh Daya Ledak Otot Tungkai dan Keseimbangan terhadap Kemampuan Jump Shoot Atlet Bolabasket FIKUNP. 